\section{Transparencia y comunicación financiera}

André Menanteau *

\begin{abstract}
Resumen: En este artículo, el autor hace foco en la bondad de la modernización de los procesos financieros, la apertura de las comunicaciones y cómo todo esto beneficia al país, al sistema financiero, a los públicos de interés y finalmente, a los consumidores. Lo interesante de este proceso que se ha acelerado tremendamente en los últimos 10 a 15 años-, es que analizado desde el punto de vista de las comunicaciones, ha generado un efecto cascada que va mucho más allá de la transparencia y de la obligatoriedad de hacer bien las cosas. Ha provocado, como se explicita en el texto, un cambio de paradigma en las comunicaciones como se conocían hasta ahora: ha cambiado el rol del vocero corporativo, el rol de las empresas de comunicaciones, el rol de la prensa especializada como intermediario en la entrega de la información, el rol de las compañías en materia de gobierno corporativo y de su relación con los stakeholders e incluso el rol del consumidor final.
\end{abstract}

Palabras clave: comunicación corporativa - comunicación financiera - consumidor - gobierno corporativo - prensa - stakeholders - transparencia.

[Resúmenes en inglés y portugués en las páginas 105-106]

(*) Periodista, Universidad Gabriela Mistral (Chile) y Diplomado en Comunicación Estratégica, Pontificia Universidad Católica de Chile. [Ver CV completo en página 141]

"Es mas fácil que un hombre perdone al que ha matado a su padre, que perdone a aquél que le ha quitado la herencia de su padre" (Maquiavelo).

El título de este paper, "Transparencia y comunicación financiera" puede sonar como un proceso evidente y correlativo. Como el título de la película de Woody Allen: Robó, huyó y lo atraparon. Tal vez porque tras los grandes escándalos que acechan al sistema financiero mundial de cuando en cuando, imaginamos que, justamente "transparencia e información financiera" deben, si no ir de la mano, estar al menos relacionadas.

Y al parecer, este es un camino que sí se está dando. A nuevos escándalos (Enron, subprimes, Madoff, entre otros), nuevas regulaciones hacen que el sistema deba ser más transparente, entendiendo por transparencia una mayor entrega de información al mercado sobre cualquier acto que pueda influir en el desarrollo futuro de alguna compañía.

Esto, así planteado, y tal y como las empresas lo utilizan en sus comunicaciones, debería ser 
bueno, y las razones que entregan los reguladores chilenos (Superintendencia de Valores y Seguros, Superintendencia de Bancos e Instituciones Financieras, Superintendencia de AFP, etc.) para solicitar más y más apertura, también deberían traer solo buenas consecuencias. Entonces éste simplemente debería ser un paper muy positivo que trate acerca de la bondad en la modernización de los procesos financieros, la apertura de las comunicaciones y cómo todo esto beneficia al país, al sistema financiero, a los públicos de interés y finalmente, a los consumidores. $\mathrm{Y}$ aunque en gran medida puede ser así, lo interesante de este proceso que se ha acelerado tremendamente en los últimos 10 a 15 años-, es que analizado desde el punto de vista de las comunicaciones, ha generado un efecto cascada que va mucho más allá de la transparencia y de la obligatoriedad de hacer bien las cosas. Ha provocado como veremos a continuación, un cambio de paradigma en las comunicaciones como las conocemos hasta ahora: ha cambiado el rol del vocero corporativo, el rol de las empresas de comunicaciones, el rol de la prensa especializada como intermediario en la entrega de la información, el rol de las compañías en materia de gobierno corporativo y de su relación con los stakeholders e incluso el rol del consumidor final.

\section{Transparencia e información financiera: ¿algo en común?}

Normalmente en los negocios hay un paradigma: actuar antes y actuar primero. La clave de los negocios, el poder del empresario está justamente en la información. Saber y usar primero aquella información valiosa que su competencia desconoce.

No hay un negocio en aquello que todos saben. No hay sorpresa en vender algo que ya existe, tal y como existe. De ahí que históricamente los hombres de negocios y las compañías a las que representan, han tratado de guardar sigilo de sus operaciones. El tema es que, con el tiempo, no son los grandes inventos o las patentes, los motivos del silencio. La falsificación de cifras, el ocultamiento de información que favorezca a unos pocos en detrimento de los demás, y las malas prácticas, es justamente aquello que ha llevado a las mayores crisis financieras de la década; ya sea por una compañía en bancarrota haciendo creer a sus inversionistas que se encuentra en su mejor momento o en Latinoamérica como hemos visto tantas veces, a causa de los cambios en las reglas del juego de los actores de turno en los gobiernos que sacan sus tajadas.

De lo expuesto, la transparencia financiera busca cuidarnos, advertirnos y, cuando es tarde, tener el camino trazado para llegar al inicio, al big bang del fraude.

Latinoamérica ha sufrido y aprendido de las crisis globales que han impactado su economía. En las décadas de los ' 80 y ' 90 las recesiones del año 82 que llevaron a un efecto que duró casi hasta el fin de la década y las crisis denominadas tequila en México en 1994/1995; samba en Brasil en 1998/1999, y tango, en Argentina en 2001/2002 y ahora recientemente con los grandes escándalos corporativos globales han fortalecido a las instituciones reguladoras, intentado otorgar más independencia de los vaivenes de la economía mundial, y mejorando el sistema financiero de modo de minimizar los riesgos que cualquier agente interno o externo pueda ocasionar. 


\section{El cambio de roles}

La experiencia profesional me ha llevado a estar en el rol del reportero de negocios como en el de director de comunicaciones de grandes empresas. Y, en este tiempo, he percibido como casi sin notarlo, este avance en la transparencia en la entrega de la información ha llevado a un cambio fundamental en los roles de los medios, de las compañías y sus voceros, afectando al mercado y al consumidor final.

En primer lugar, hace no más de una década, la mayoría de los medios de comunicación en Chile y en Latinoamérica estaban recién orientándose a la especialización en materia financiera. Los propios procesos de apertura democrática del continente, la desregulación de algunos de sus mercados claves, el ingreso de capitales extranjeros y la globalización financiera generaron noticias. La consigna era clara: ahí donde hay oportunidades de invertir, donde hay rentabilidad, hay información relevante.

En esa época, todos los medios competían por titulares, por golpes noticiosos, al igual que ahora, pero con una pequeña, aunque significativa diferencia. La información era menos pública y escasa. Las compañías hablaban de sus planes y los medios publicaban cifras cada día. De ahí que el resultado final de cualquier empresa, sus proyecciones de crecimiento, aún cuando la información viniera de la propia compañía como fuente, eran noticias de portada. El anuncio de planes de inversión a 10 años que nadie nunca más podía constatar o simplemente la idea de comprar, vender o fusionar eran puestas en letras de molde de inmediato. Mientras más números había en una nota informativa o en un titular mejor.

Todo eso ha ido cambiando. Al principio lentamente, pero en los últimos cinco años en forma muy veloz y como una necesidad. Y esta ha sido tal vez una de las principales transformaciones que ha provocado la apertura de los mercados y la transparencia en la entrega de la información. Mirábamos entonces con cierta envidia los medios norteamericanos o europeos que hacían análisis, que hablaban de temas profundos, que buscan más el por qué que el qué, pero ya no ocurre eso.

$\mathrm{Al}$ conversar con editores de medios financieros me comentaban justamente de este cambio. Hoy es casi imposible "golpear" con una noticia. Toda la información está obligatoriamente disponible y en línea. De ahí que el "nuevo periodista” debe buscar más allá y la pregunta relevante es dónde buscar, y ese es probablemente el efecto cascada más importante de este nuevo modelo. Esa búsqueda ha llevado a que las compañías cuiden más que nunca su reputación. Una operación cuestionable al otro lado del globo o un mero problema de discriminación laboral pueden valer hoy más que años de utilidades y rentabilidad asegurada. Cuando todo está puesto encima de la mesa, hay que buscar que hay debajo. Cuáles son las otras razones que no vemos y que sostienen o no la estructura de una corporación.

Así como el rol de las empresas u organizaciones es ser transparentes y veraces, el rol del periodista (encomendado por el ciudadano común) es cuestionar y no aceptar las verdades de buenas a primeras. Hoy, que cada vez hay más transparencia, se escudriña más y de manera más profunda para obtener los datos que sean noticia. 


\section{El rol de la prensa y la saturación de información}

Hoy está claro, salvo algunos países vecinos, los niveles de transparencia en materia de información de las empresas son muy rigurosos. Esa ha sido la tendencia de los últimos años y avanza de manera acelerada.

Ya no solamente existe una cantidad mucho mayor de información disponible, sino que además está en línea y al instante para cualquier persona en el mundo donde exista un computador e Internet. La pregunta es qué hacemos con toda esa información, cuánto efectivamente nos sirve y cómo vamos a ser capaces de filtrar y procesar todos esos datos.

Probablemente la respuesta será que es imposible, y que dejamos en manos de otros el desarrollo de este proceso: principalmente los medios de comunicación. En un rol renovado, más acucioso, más profundo y más analítico, es la prensa la que hoy sigue siendo, al igual que antes, el referente principal y oficial en la entrega de los datos relevantes.

Recuerdo que hace unos 20 años, haciendo la práctica profesional en un diario especializado en finanzas tenía que ir, al final de la tarde, a buscar los denominados "hechos esenciales" (información relevante que las empresas están en obligación de comunicar al mercado) a la Superintendecia de Valores y Seguros. "Ir a buscar" era literalmente bajar al subterráneo, fotocopiar los documentos que habían llegado, meterlos a mi maletín y llevarlos al diario. Ahí revisarlos y ver en cuál de ellos había noticias. Hoy, cualquier persona, incluidos obviamente los periodistas tiene acceso a esa información entre mucha otra, que está a libre disposición de los usuarios. El problema es que ya no cabría en el maletín que usaba en esa época.

Hoy la información disponible es mucha y se refiere a miles de temas que pueden ser menores y sin importancia para casi cualquier persona. Incluso los corredores de Bolsa, los inversionistas y cualquiera que tenga mecanismos de alerta en sus teléfonos móviles, después de unos días simplemente dejará de revisarlas, excepto que sean noticiosas.

Lo mismo pasa con los medios. Por definición, si la información financiera es pública, no es noticia. ¿Por qué alguien debiera pagar por leer en un papel aquello que puede encontrar gratis en la red?. Y qué pasa cuando la mayoría de la información que antes era motivo de noticia, ahora es pública: ¿Se sigue informando? ¿Qué se informa ahora?

Pues bien, los medios siguen siendo el referente oficial de la información. Ya sea que lo critiquemos o no, aquellas noticias impresas en los periódicos son de alguna forma el último paradigma, de ahí que éstos han debido adaptar su forma de hacer noticia y buscar un giro en la entrega de sus contenidos.

El editor de un medio, hace muy poco me señalaba que ya casi es imposible lograr un golpe noticioso como se hacía antes. Las empresas ya no comunican por canales no oficiales y resultaría impensable que un medio de comunicación se entere y entregue información relevante para el mercado previo a que ésta haya sido informada a la autoridad.

Quienes trabajamos en consultoras de relaciones públicas sabemos que los principales ejecutivos de las compañías a las cuales representamos tienen órdenes estrictas de no hablar con la prensa sin estar preparados acerca de cuál será su discurso. Y si antes esas "ordenes" podían ser desobedecidas, hoy la ley las ha convertido en un mandamiento ineludible. 


\section{El consumidor}

Conversando con gerentes de finanzas de grandes empresas ligadas al consumo masivo y con consultores de comunicaciones llegábamos a la misma conclusión. Cualquier cosa que la empresa haga en materia de transparencia financiera tiene poco o nulo impacto en la decisión final de compra de un individuo o en su valoración como compañía. No se crea una "lovemark" entregando información financiera. No obstante, existen públicos intermedios que sí están obligados a llevar cuenta de lo que ocurre.

En un estudio realizado por el periódico español Expansión en septiembre de 2009, sobre "Comunicación con Inversores y Analistas en Tiempos de Crisis" se señalaba que "En el mercado se vigilan de cerca los movimientos en las participaciones significativas y en la autocartera de la compañía. Que los consejeros y directivos de una empresa aumenten o disminuyan su participación en la misma de forma importante puede ser una pista fiable sobre la confianza que tienen en el futuro de la compañía. La evolución de la acción y del capital de la sociedad es otro de los temas que en el mercado se le presta atención".

Lo relevante al respecto es que el mismo sondeo, efectuado a 222 inversores accionistas, analistas, gestores de compañías de capital riesgo, ejecutivos de family office, gestores de fondos de inversión y agentes de bolsa es que a nivel de valor, "asuntos tan llamativos como el gobierno corporativo, que está en muchos debates para su potenciación, no alcanzan el aprobado. Los encuestados tampoco dan importancia a la agenda del inversor y tener acceso a la relación de analistas especializados".

Es decir, en este análisis debemos de inmediato despejar una variable. No son las personas o el consumidor final, por decirlo de algún modo, un público que sea tomado en cuenta a la hora de mantener una política de transparencia financiera. Se apunta directamente a otros stakeholders: accionistas, inversionistas y reguladores. Las personas, cada día sometidas a la decisión de comprar entre un bien u otro no se ven influidas en ninguna forma por los estados financieros o la mejor estructura de un gobierno corporativo de alguna marca que sí les de tranquilidad a los organismos reguladores.

Es decir, las personas no hacen (o no estaban haciendo y aquí está el punto) ningún nexo entre la salud financiera de una empresa y sus preferencias. Hoy, en la góndola de un supermercado, nadie prefiere una leche sobre otra porque la clasificación de riesgo de su fabricante es mejor. La razón es muy simple, para cualquier individuo simplemente no hay relación.

Pero todo cambia. $Y$ hace 50 años tampoco las personas miraban detenidamente los índices de seguridad de los vehículos, el índice de sodio o de tartrazina en un alimento. Hoy, como mencionábamos recientemente, a causa de esta nueva oleada de necesaria y obligatoria transparencia en la información financiera, los medios de comunicación -que siguen siendo "el" nexo entre las empresas y las personas, han cambiado su foco y modificado sus noticias. Han transformado términos como: transparencia, ebitda, razón de endeudamiento, créditos, crecimiento, cartera crediticia y colusión, por mencionar algunas, en una sola y gran palabra: "reputación".

Así, ya no basta con publicar los resultados corporativos para cumplir con lo requerido por el fiscalizador, y sabiendo con certeza que una dueña de casa (por poner el ejemplo más extremo) no visualizará la relación entre "deudas por vencer" en una compañía y su detergente en oferta. Pero así como algún día tampoco vimos relación entre productos baratos y fábricas con malas 
prácticas laborales, hoy la globalización y la apertura nos facilitan esos nexos.

Una prueba de ello es que en junio de 2011 una de las compañías modelo de crecimiento en el retail en Chile sufrió el desplome de su acción en más de $40 \%$, sus ejecutivos, su directorio, están son actores del proceso de investigación y la transacción de los títulos de la compañía quedó detenida hasta que establecer los reales alcances de la crisis.

La razón de la crisis es netamente financiera, pero lo verdaderamente relevante es que fue gatillada por sus clientes. Con todas las reglas de transparencia, con todos los controles existentes, fue justamente un grupo de consumidores quien dio la voz de alerta acerca de las modificaciones unilaterales que las multitiendas "La Polar" estaba haciendo con los deudores de sus tarjetas comerciales. Así, un grupo de consumidores de los sectores socioeconómicos más bajos (que es justamente donde apunta el segmento de esta tienda de departamentos) sacó la voz ante la autoridad que los respalda y con el apoyo de la prensa, una noticia que simplemente constituía abuso de poder en el proceso de renegociación unilateral de los créditos vencidos de estas personas, terminó destapando un escándalo financiero de proporciones mayores.

Entonces la noticia ya dejó de ser solo la de un grupo de personas abusadas por una casa comercial y pasó a ser la de una compañía que deberá provisionar incobrables por un monto indeterminado, estimados entre algo más de US\$ 400 millones y US\$1.000 millones.

Allí donde ningún mecanismo funcionó, donde una compañía era presentada como "la joya del retail", donde las autoridades no pudieron prever la crisis con todas las reglas de transparencia existentes, donde las clasificadoras de riesgo entregaban resultados favorables y todo el sistema financiero confiaba en entregar créditos; las demandas colectivas de las personas hicieron ver la realidad.

La lección: sí hay un nexo muy importante entre el consumidor informado, la transparencia y la reputación corporativa. Y este vínculo con el tiempo se hace más fuerte y es finalmente lo que nos protege como consumidores, y en esta cadena, la prensa como filtro, como analista al separar lo importante de lo accesorio de tanta información financiera que nos bombardea día a día, tiene un rol preponderante que jugar.

En su columna de opinión titulada "Causas y Consecuencias de nuestra Crisis Subprime: La Polar" en el diario La Segunda de Chile (2011), el economista y ex Superintendente de Valores y Seguros del gobierno de la ex Presidenta de Chile, Michelle Bachelet, Guillermo Larraín señalaba:

La Polar es la versión chilensis de la crisis subprime: ocurrió en una empresa de propiedad diluida -como las empresas norteamericanas protagonistas de la crisis- cuyo foco de desarrollo eran segmentos socioeconómicos medios y medios bajos.

Lo que imagino que ocurrió es que durante la crisis, ante el incremento en la morosidad, la empresa reprogramó las cuentas impagas. Lo hizo de una manera tal que las reprogramaciones generaban utilidades. Si los clientes reclamaban, se debe haber negociado una salida más o menos consensuada.

Lo que detonó la debacle es que el SERNAC (Servicio Nacional del Consumidor de Chile) inició una acción judicial colectiva producto de la acumulación de reclamos. Ahí ya no es posible negociar uno a uno y en condiciones favorables. Contra una masiva acción de este tipo y ante la evidente ilegalidad de las reprogramaciones previas, lo más probable es que esas cuentas por cobrar se hagan, 
a montos menores que los que reconocía la empresa. La estimación es que un $25 \%$ de esas cuentas no se podrían cobrar porque su monto obedece a reprogramaciones y eventualmente tasas improcedentes.

Respecto al mismo punto, el Gobierno de Chile ha señalado explícitamente la relevancia que tiene el caso, en primer lugar hacia los consumidores y luego, como debilitamiento del mercado. El ex ministro de Economía, Juan Andrés Fontaine, señaló al diario electrónico EMOL (2011) que: "la denuncia a La Polar constituye una violación muy grave a los derechos de los consumidores y, además, una falta de transparencia respecto de la información entregada a los mercados". "...se trata de un hecho lamentable que desgraciadamente ocurre de cuando en cuando y que debe ser rectificado con las medidas correspondientes".

Es decir, en las condiciones actuales del mercado, la transparencia en la información financiera por sí misma no genera cambios. Las personas no la asimilan como tal y no son capaces de procesarla, pero la cascada de reacciones que se generan al tener el mercado saturado de información y en permanente análisis, hace que cualquier denuncia, por pequeña que pueda ser y aunque ésta provenga de grupo minoritario, pueda desencadenar una reacción masiva.

\section{Las empresas, las comunicaciones corporativas y la transparencia financiera}

En los media training a los que he asistido (o dictado), siempre he oído en distintas versiones el concepto "Diga siempre la verdad. La mentira no es solamente moralmente inaceptable, sino que la sanción social por ocultar lo hechos conlleva a consecuencias nefastas para la reputación". El punto es que, siempre lo que sigue a esta frase es la aclaración: "Diga la verdad, solo la verdad, pero no TODA la verdad".

Y la razón es muy clara, sabemos que en comunicaciones corporativas, cuando nos referimos a "toda la verdad", estamos hablando, la mayoría de las veces, de información confidencial.

Conversando con el gerente de finanzas de una gran empresa me señalaba que más que hablar de transparencia en la información financiera, se debiera hablar de transparencia total. Que no tiene sentido que algunos pocos sepan de información que la mayoría desconoce.

Por ejemplo, en el mercado es una práctica habitual que las compañías deban atender a los analistas para responderles preguntas relevantes respecto al futuro de la compañía o para entender en profundidad los alcances de una u otra medida que enfrentan. Pero, ¿por qué ese analista, puede llevarse la misma información que es pública, pero analizada y con la claridad que determinadas medidas pueden implicar al mediano o largo plazo?

Es ahí donde las compañías fallan y deberían estar obligadas a entregar una mayor información hacia todos sus públicos. No basta la transparencia, hay que explicarla. Nuevamente, la entrega de información, no es lo mismo que la comunicación. Y el exceso de información, más bien causa la falta de comunicación.

Entre las medidas que pueden adoptar las empresas en tiempos difíciles, el aumento de la transparencia resuena en todos los discursos. "Deberían hacer más road-show (encuentros con expertos), una presentación al año es insuficiente para dar a conocer a la compañía", proponen desde un family office. "Cuanto 
más se comunique y más transparente sea la empresa, mejor", asegura un agente de bolsa. Para algunos gestores no es una cuestión de esfuerzo económico, sino de transparencia. "No tanto incrementar el esfuerzo, pero sí ser claros", reclama un gestor (Expansión, 2009).

En este caso nos encontramos con la aplicación más clara de lo que he venido señalando: La transparencia financiera por sí sola es útil en una medida muy diferente a la que en comunicaciones creemos. La transparencia tiene un fin y un sentido puro solo desde el punto de vista de la autoridad, pero no hacia la opinión pública.

Desde los cambios en la forma de buscar y escribir una noticia, hasta el modo en que una compañía se ha tenido que relacionar con todos sus públicos de interés, llegando hasta el consumidor final, son una consecuencia que se desprende de la búsqueda de la transparencia, pero no como un efecto inmediato.

A modo de ejemplo inverso. Si yo estoy obligado como vecino a mantener el silencio en la comunidad donde vivo, mis vecinos no me respetarán por lo silencioso que soy. Más aún, en este silencio normal en que se va a encontrar la comunidad, mis vecinos aguzarán el oído y ya no reportarán sólo cuando haya una fiesta o alguien esté taladrando un muro a las tres de la mañana. Estarán atentos al llanto de un niño, a la pelea de una pareja o a los gritos de una mujer. O tal vez a la falta de sonidos en un departamento en particular. Todo comenzaría a ser más sospechoso. Quien quiera cometer una falta, deberá guardar más precauciones. El respeto del silencio, por ende, en este caso, y llegando a un extremo, no es una causa ni fue pensado para obtener mayores denuncias de violencia doméstica, pero podría serlo.

Es en este nuevo escenario de mayor transparencia, donde quienes ejercemos en áreas o consultoras en comunicaciones nos hemos ido dando cuenta de una gran paradoja que ya he mencionado en este paper: mientras más transparencia es obligada por la autoridad, por lo general, más silencio guardan las compañías a través de los medios masivos, que es justamente la fuente de información para las personas.

Ya casi nadie levanta el teléfono para anunciar una exclusiva a los medios o habla con la prensa a la salida de un seminario o de un cocktail. Ahora los ejecutivos desaparecen en perfecto silencio, con mucho cuidado de no herir las susceptibilidades de los medios, pero sin emitir declaraciones. Todo será informado a su tiempo a través de los canales oficiales y, seguramente, lo derivarán a través de su encargado de prensa.

"Cada vez es más difícil para ustedes tapar con buenas noticias los errores de las empresas", me expresaba hace poco un periodista. Y claro, en una visión caricaturizada de lo que son las relaciones públicas o las comunicaciones organizacionales.

Cada vez, podríamos decir, es más difícil lograr publicar noticias que sean interesantes para los medios. Si las cifras ya son públicas, así como las inversiones relevantes o las fusiones; si los nuevos productos son publicidad y si en general las buenas noticias, no son noticias....el desafío entonces es buscar aquello que no estamos obligados a hacer como empresa y lo hacemos de igual forma. RSE, sustentabilidad medioambiental, buenas prácticas. Todas ellas nos ayudarán a que en el tiempo podamos lograr no sólo obtener de nuestros públicos la legitimidad, sino también la afectividad. Es decir, que nos quieran.

Es siempre más difícil para un adversario derrotar a una empresa querida, y siempre un con- 
sumidor que está atento de las buenas prácticas de una empresa, estará dispuesto a darle una segunda oportunidad.

Una vez más, como una derivada del nuevo escenario de transparencia en las comunicaciones a las cual las empresas se han debido acostumbrar, hay una oportunidad para la generación de reputación corporativa en base a las buenas prácticas. Ahí donde antes lo que valía eran las cifras y las inversiones, hoy hay muchos espacios que las empresas no pueden dejar abiertos. Nadie quiere que sus productos y que el valor de su marca caiga por hechos que, hasta hace muy poco, apenas eran conocidos o escrutados por los medios y evaluados al momento de tomar una decisión de compra.

En resumen, transparencia en la información financiera y comunicación son, cuando mucho, parientes lejanos. Nacen en diferentes familias, con diferentes padres y toman caminos separados, pero al final igual que en las teleseries, están siempre íntimamente relacionadas. Los aparentemente imperceptibles, pero drásticos cambios que produce en todo el sistema el hecho que mucha información esté siempre disponible, y por ende, de alguna forma deje de ser noticia, genera desafíos fundamentales para toda la pirámide de actores que tienen a su cargo el proceso de comunicar e informar.

Los nuevos roles de la prensa, las compañías, sus empresas y asesores de prensa, los entes fiscalizadores y finalmente el consumidor final se han ido adaptando a este nuevo escenario, que al largo plazo, y a pesar de las caídas en la bolsa y los escándalos financieros que leo en este preciso momento en el diario que está al lado de mi computador, se ve como un camino sin vuelta hacia una mejor forma de hacer sociedad.

\section{Referencias Bibliográficas}

Emol.com (2011). Sernac espera que La Polar proponga una solución a los clientes. Disponible en: http://www.emol.com/noticias/economia/detalle/detallenoticias.asp?idnoticia $=486619$

Expansión.com (2009). Estudio sobre la comunicación con inversores y analistas en tiempos de crisis. Los datos financieros y el dividendo son los temas que más interesan a los accionistas. Disponible en: http://www.expansion.com/2009/09/27/inversion/1254082864.html?a=d2f89 661427ed93a12137ef166d366ca\&t $=1308083841$

La Segunda Online. (2011). Causas y consecuencias de nuestra crisis subprime: La Polar por Guillermo Larraín. Disponible en: http://blogs.lasegunda.com/redaccion/2011/06/13/causas$\mathrm{y}$-consecuencias-de-nues.asp

Summary: In this article, the author focuses on the kindness of financial processes modernization, the opening of the communications and how them benefits the country, the financial system, the public interest and the consumers. The interesting thing of this process that has accelerated tremendously in the last ten to fifteen years, is that from the point of view of communications, it has generated a difusing effect that goes beyond transparency and the obligatory nature of doing things well. It has caused a shift of paradigm in the communications as they were known up today; it has changed the role of the corporate spokesman, the role of 
communications companies, the role of the press as intermediary in the delivery of the information, the role of the companies in the matter of corporate governance and their relation with stakeholders and even the role with consumers.

Key words: consumer - corporate communication - corporate governance - financial communication - press - stakeholders - transparency.

Resumo: Neste artigo, o autor faz o foco na bondade da modernização dos processos financeiros, a apertura das comunicações e cómo tudo benefícia ao país, ao sistema financeiro, aos públicos de interesse e finalmente, aos consumidores. $\mathrm{O}$ interesante de este processo que se acelerou nos últimos 10a 15 anos, é que analisado desde o ponto de vista das comunicações, há gerado um efeito bola de neve que vai mais lá da transparência e da obrigatoriedade de fazer bem as coisas. Há provocado, como se explica no texto, uma mudança de paradigma nas comunicações como se conheciam até hoje: ha mudado o papel do porta-voz, o papel das empresas de comunicações, o papel da prensa especializada como intermediário na entrega da informação, o papel das companhias em matéria de governo corporativo e de sua relação com os stakeholders e inclusive com o consumidor final.

Palavras chave: comunicação corporativa - comunicação financeira - consumidor - governo corporativo - prensa - stakeholders - transparência. 